\title{
Clearance of proteoglycan from joint cavities
}

\author{
D P PAGE-THOMAS, D BARD, B KING, AND J T DINGLE \\ From Strangeways Research Laboratory, Worts Causeway, Cambridge
}

SUMMARY The rate of loss from the synovial cavity of proteoglycan subunit, a major constituentof cartilage, has been measured in rabbits with and without experimental arthritis. The effect ofs

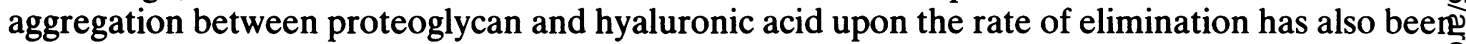
investigated. The results indicate that proteoglycan subunit has a clearance half life of around $12^{2}$ hours in normal joints and that this rate is not significantly altered in the presence of an active synovitis. Neither injection of proteoglycan as an aggregate, nor in a form incapable of aggregation, had any significant effect on clearance rates. These data indicate that loss of proteoglycan from the joint is not retarded by its ability to aggregate with hyaluronic acid in the synovial fluid and, together with measurements of synovial fluid proteoglycan, may enable rates. of cartilage breakdown in vivo to be calculated.

Key words: experimental arthritis, rabbits, articular cartilage, glycosaminoglycans, metabolism $\frac{\mathbb{\infty}}{乛}$ synovial fluid, synovium.

The characteristic joint lesions in osteoarthritis (OA) and rheumatoid arthritis (RA) are associated with loss of proteoglycan and collagen from the articular cartilage. Recent work has indicated that measurement of proteoglycan in synovial fluid may be a relatively simple and reliable means of determining the rate of loss of proteoglycan during the disease process. Saxne et al in Lund using immunochemical methods ${ }^{1}$ and $G$ Carroll at the Strangeways Laboratory using a chemical method (personal communication) (which correlated well with immunochemical assays) demonstrated the presence of substantial quantities of glycosaminoglycans (GAGs) in synovial fluids. Dingle et al have assayed GAG levels in over $150 \mathrm{OA}$ and RA fluids. ${ }^{2}$ The chemical methods involve a modification of the dimethylmethylene blue assay technique for proteoglycans. ${ }^{3}$ This method can also be applied to animal synovial fluids. Dingle et al showed that the treatment of rabbit knee joints with a synovial interleukin 1 preparation caused a loss of articular cartilage proteoglycan and a concomitant rise of GAGs in the synovial fluid. ${ }^{4}$ To establish the quantitative relation between the level of GAGs in synovial fluid and the rate of loss from the articular cartilage it is necessary to determine the clearance rate of proteoglycan from the synovial fluid. The

Accepted for publication 31 May 1987.

Correspondence to Dr D P Page-Thomas, Strangeways Research Laboratory, Worts Causeway, Cambridge CB1 4RN, UK. work described in this paper measures the clearance rate of aggregate, subunit, and non-aggregatasie subunit from rabbit knee joints.

\section{Materials and methods}

The proteoglycan was prepared from bovine naså septa by the method of Heinegard, ${ }^{5}$ and part of the $\overrightarrow{0}$

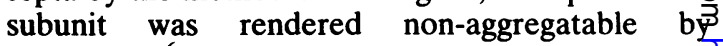
acetylation. ${ }^{6}$ Proteoglycan aggregate, subunit, non aggregatable subunit, and bovine serum albumin. (BSA) (Sigma Chemical Co, Poole, Dorset) were labelled with ${ }^{131}$ I using 'Iodobeads' (Pierce Chemi cal Co, Rockford, Illinois). ${ }^{7}{ }^{131}$ I (specific activity. $500 \mathrm{MBq} / \mu \mathrm{g}$ ) (Amersham International, Aylesbury. Bucks) was added to a solution of the appropriate protein $(1 \mathrm{mg} / \mathrm{ml})$ in phosphate buffered saline, $\mathrm{pH}$ $7 \cdot 35$, to give a final radioactive concentration of 37 $\mathrm{MBq} / \mathrm{ml}$. One Iodobead was added for each $\mathrm{ml}$ of solution and the reaction mixture was allowed to stand with occasional agitation for 10 minutes. The Iodobeads were then removed and carrier sodium iodide added to give a final concentration of 108 $\mathrm{mg} / \mathrm{ml}$. This solution was dialysed for a total of $72 \mathrm{~b}$ in two changes of deionised water and a third of physiological saline. All the above procedures were carried out at $4^{\circ} \mathrm{C}$. Labelling by this method yielde products with specific activities of between 4 and 8 $\mathrm{MBq} / \mathrm{mg}$ protein. The subunit, aggregate, and acetylated subunit were characterised on Sepharose 2BCL column and did not appear tक 
suffer any change in molecular size or in ability to aggregate after iodination.

\section{ANIMAL EXPERIMENTS}

Rabbits were of the Old English strain and between 3 and 9 months old. Unilateral experimental arthritis ${ }^{8}$ was induced in the knees of some of these animals 21 days before the following experiments were carried out.

The rabbits were sedated with 'Hypnorm' $(0 \cdot 4$ $\mathrm{ml} / \mathrm{kg}$ ) (Janssen Pharmaceuticals, Beerse, Belgium) and $0.4 \mathrm{ml}$ of a radiolabelled protein solution injected into the synovial cavities of their knees. The rabbits were positioned rapidly with their knees underneath vertical, lead collimated, gamma scintillation probes and the radioactivity measured as previously described. ${ }^{9}$ Counting was repeated at

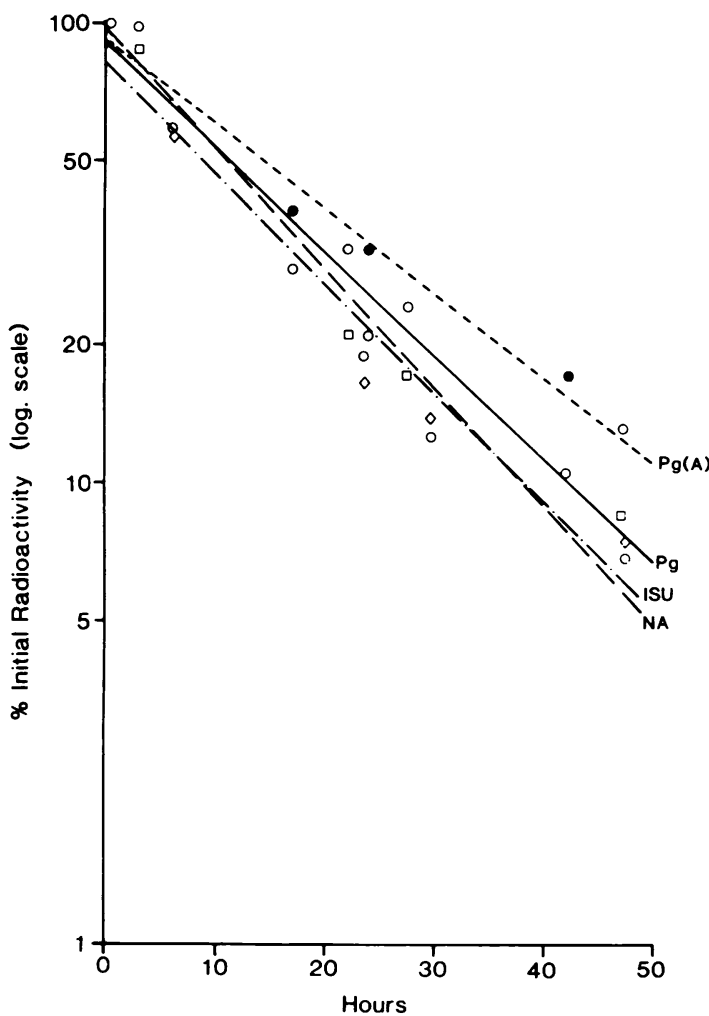

Fig. 1 Loss of proteoglycan subunit preparations from normal and experimentally arthritic rabbit knees: $\mathrm{O}-\mathrm{O}$ $P g=$ proteoglycan, normal knees;

$\operatorname{Pg}(A)=$ proteoglycan, arthritic knees; $\square--\square$

$N A=$ non-aggregatable subunit, normal knees; $\diamond-一 . \diamond$ ISU =inhibited (acetylated) subunit, normal knee. Points represent pooled results for each time point and the lines are least mean squares fits to the respective data.
Table 1 Clearance rate of proteoglycan preparations in normal and arthritic rabbit knees

\begin{tabular}{|c|c|c|c|c|}
\hline \multirow[t]{2}{*}{ Preparation } & \multicolumn{2}{|l|}{ Normal knees } & \multicolumn{2}{|c|}{ Arthritic knees } \\
\hline & Half life $(h)^{*}$ & $n$ & Half life $(h)$ & $n$ \\
\hline $\begin{array}{l}\text { Proteoglycan aggregate } \\
\text { Proteolytic proteoglycan }\end{array}$ & $12 \cdot 94(0 \cdot 63)$ & 14 & $14.49(2 \cdot 58)$ & 5 \\
\hline subunit & $12 \cdot 47(0.68)$ & 4 & $\mathrm{ND}+$ & \\
\hline Non-aggregatable subunit & $12.47(0.34)$ & 5 & ND & \\
\hline $\mathrm{BSA} \dagger$ & $3.91(0.81)$ & 3 & ND & \\
\hline Sodium pertechnetate & $0 \cdot 82$ & 1 & 1.78 & 1 \\
\hline
\end{tabular}

*Values are mean (SEM).

†BSA=bovine serum albumin; $\mathrm{ND}=$ not determined.

intervals for periods of up to $48 \mathrm{~h}$, and in some experiments the animals were then killed by means of an intravenous injection of 'Euthatal' (May \& Baker Ltd, Dagenham, Essex). The joints of these animals were opened, the synovial fluid collected, the synovial cavity washed twice with $0.25 \mathrm{ml}$ physiological saline, and the synovial fluid combined with the washings. The synovium was also removed. The tissues and the joint washings were weighed and their radioactivities counted on a Packard MultiPrias 4 gammacounter using a window of $15-500$ $\mathrm{keV}$. All radioactive measurements were corrected for the decay of ${ }^{131} \mathrm{I}$ (half life 8.07 days).

\section{Results}

Radiation measurements over the knees declined exponentially with time (Fig. 1) $(r>0.9)$ with all of the preparations injected. It was thus possible to calculate the clearance rate from the knee in each case as a half life, and these values are summarised in Table 1. All the proteoglycan preparations had clearance half lives of between 12 and 13 hours in normal (non-arthritic) joints, and although the mean value for total proteoglycan subunit was slightly higher than this in arthritic joints, the difference was not significant (Table 1). Removal of the aggregatable fraction from the injected material, or rendering the proteoglycan non-aggregatable by acetylation had no effect on its clearance from joints. Proteoglycan was, however, released significantly more slowly than BSA (Table $1 ; \mathrm{p}<0 \cdot 001$ ).

Measurements of the residual radioactivity in the synovium and the synovial cavity showed that at $42 \mathrm{~h}$ after injection of proteoglycan subunit into normal joints a total of 1.63 (SEM 0.23 )\% of the injected radioactivity could be recovered from the joint, with approximately half in the synovial fluid and the remainder in the synovium (Table 2). The total radioactivity recovered and its distribution between synovial fluid and the synovium were not signifi- 
Table 2 Recovery of radioactivity from the synovium and synovial fluid $42 \mathrm{~h}$ after intra-articular injection of proteoglycan subunit preparations

\begin{tabular}{llll}
\hline Preparation & Synovial fluid & Synovium & Total \\
\hline $\begin{array}{l}\text { Subunit } \\
(\text { normal knee) } \\
(n=9)\end{array}$ & $0.89(0.21)^{\dagger}$ & $0.76(0.09)$ & $1.63(0.23)$ \\
$\begin{array}{c}\text { Subunit } \\
(\text { arthritic knee) } \\
(n=5)\end{array}$ & $1.48(0.46)$ & $1.57(0.46)$ & $3.06(1.14)$ \\
$\begin{array}{c}\text { Non-aggregatable } \\
\text { subunit (normal } \\
\text { knee) (n=4) }\end{array}$ & $0.22(0.11)$ & $0.57(0.04)$ & $0.79(0.13)^{*}$ \\
\hline
\end{tabular}

${ }^{*} \mathrm{p}<0 \cdot 05$.

+ Values are mean (SEM) and given as a percentage of the total radioactivity injected.

cantly different in experimentally arthritic joints. Less radioactivity remained, however, in normal joints injected with non-aggregatable material $(\mathrm{p}<0.05)($ Table 2).

\section{Discussion}

Saxne et al have shown using immunoassay techniques that substantial quantities of proteoglycan are released into the synovial fluids of patients with various knee joint arthritides. ${ }^{1}$ Levels of proteoglycan antigen of the order of $5-10 \mathrm{mg} /$ joint were reported. In a preliminary communication Dingle $e t$ al have used chemical assays for glycosaminoglycans to determine GAG levels in some 150 synovial fluids from arthritic patients. ${ }^{2}$ Mean values of $200 \mu \mathrm{g} / \mathrm{ml}$ (range $45-500 \mu \mathrm{g} / \mathrm{ml}$ ) were found in a population of rheumatoid patients and $430 \mu \mathrm{g} / \mathrm{ml}$ (range 300-800 $\mu \mathrm{g} / \mathrm{ml}$ ) in the synovial fluid of patients with osteoarthritis. When the volume of the synovial fluids is taken into account this represents approximately $5 \mathrm{mg}$ (range 1-20 mg) of GAG in joint fluid in the whole knee in the rheumatoid patients and approximately $2 \mathrm{mg}$ (range 1-2.8 mg) GAG in the joint fluid of the osteoarthritic patients-values which are similar to those obtained by Saxne et al.

When the rate at which the cartilage matrix may be lost during the course of the arthritic disease is considered these high values appear to point to a very rapid catabolic activity, bearing in mind that the intact adult human knee joint contains about 1-1.5 g GAG (Dr Baylis, Kennedy Institute, personal communication). To determine the application of these values to the turnover of the cartilage matrix it is necessary to have an estimate of the clearance rate of the GAGs from the synovial fluid. As it was unethical to carry out the necessary procedures on humans we decided to use normal and experimentally arthritic rabbits.

We used the Page-Thomas model for rabbit $\vec{\Rightarrow}$ arthritis $^{8}$ as this gives a reproducible and well? characterised lesion with a known rate of develop-등 ment. Rabbit joints are, furthermore, large enough $\overline{\bar{c}}$. to monitor reproducibly with external gamma scin- $\widetilde{\varnothing}$ tillation probes.

The results obtained show that proteoglycan is cleared from the rabbit knee with a half life of $\overrightarrow{0}$ approximately $12 \mathrm{~h}$ (Table 1 ). In contrast, the $\overrightarrow{-}$ clearance half lives of albumin (mol. wt 65000 ) and sodium pertechnetate (mol. wt 201) were approx-ฏ imately $3.9 \mathrm{~h}$ and $0.82 \mathrm{~h}$ respectively, even though 0 the pertechnetate anion becomes partially bound to protein in biological fluids. ${ }^{10}$

Proteoglycan subunit is a polydisperse macromolecule with a mean molecular weight of around $2.5 \times 10^{6}\left(\operatorname{SD~} 1.2 \times 10^{6}\right)^{11}$ and it seemed likely that itso relatively slow rate of clearance in comparison withalbumin and pertechnetate was attributable to its much higher molecular weight. It might therefore have been expected that native subunit, which has 3 the ability to aggregate with hyaluronate to form yet@ larger complexes, would be cleared even moxe $\vec{s}$ slowly than proteoglycan in which this property impaired. This hypothesis was examined by compo ing the clearance rates of proteoglycan subunit. preformed proteoglycan/hyaluronate aggregate, and proteoglycan which had been rendered incapable of aggregation by acetylation. There was no significantő difference in the clearance rates of these different $\mathcal{Q}$ preparations, suggesting that the acetylated subunit $\overrightarrow{0}$ was sufficiently large for passive diffusion to be 3 minimal and that the bulk of the material was? cleared from the joint by other processes.

Small quantities of both aggregatable and non-ஹ aggregatable material could be recovered from the synovial fluid and the synovium $42 \mathrm{~h}$ after injection. The small, but not significant increase in the retention of aggregatable material in these tissues from joints with experimental arthritis is a reflection of the larger weights of tissue and fluid recovered and does not indicate differences in tissue concen $\frac{\vec{D}}{O}$ trations. Significantly more radioactivity was, 三. however, present in normal joints injected with aggregatable as opposed to non-aggregatable ma- $\mathrm{N}$ terial $(p<0.05)$, perhaps suggesting a slower tissue breakdown rate for the aggregate.

As no figures are available for the clearance rate of proteoglycan material from human synovial fluid, and it is reasonable to assume that similar physiolo- $-\frac{\Phi}{\infty}$ gical processing applies in both the rabbit and man, one is perhaps justified in making a very cautious extrapolation from the animal clearance rates re $\frac{\vec{D}}{\mathbb{P}}$ ported in this paper to those in the human knee $\frac{\text { ? }}{\mathrm{O}}$ 
joint. If the clearance rates of approximately $12 \mathrm{~h}$ occurred also in human arthritic patients this would suggest that some patients with RA could be losing $>10 \mathrm{mg}$ of GAG/day during the active phase of the disease. Osteoarthritic patients might be losing up to a third of this quantity a day. These figures are calculated from a population of 85 patients with RA (mean $6 \mathrm{mg} /$ joint) and 57 with $\mathrm{OA}$ (mean 2.5 $\mathrm{mg} /$ joint $)^{2}$ and may be unrepresentative of the activity in any individual patient if this varies with time.

Saxne et al, however, showed that two untreated patients sampled at one and three month intervals maintained constant levels of proteoglycan. ${ }^{1} \mathrm{Un}$ published studies by Hazleman, Cawston, PageThomas, and Dingle, in which a longitudinal study of secretion of GAGs by individual patients was carried out, have shown also that the level of GAG in synovial fluid can remain high over a period of several months. Although much work remains to be done in this area, these results suggest that consideration of proteoglycan loss into the synovial fluid should be a factor in the assessment of any treatment which aims to maintain the integrity of cartilage.

This work was supported by funds from the Arthritis and Rheumatism Council and the Medical Research Council.

\section{References}

1 Saxne T, Heinegård D, Wollheim F A. Therapeutic effects on cartilage metabolism in arthritis as measured by release of proteoglycan structures into the synovial fluid. Ann Rheum Dis 1986; 45: 491-7.

2 Dingle J T, Page-Thomas D P, Hazleman B L. The role of cytokines in arthritic disease: in vitro and in vivo measurement of cartilage degradation. Int J Tissue React 1987; ix: 349-54.

3 Farndale R W, Buttle D J, Barrett A J. Improved quantitation and discrimination of sulphated glycosaminoglycans by use of dimethymethylene blue. Biochim Biophys Acta 1986; 883: 173-7.

4 Dingle J T, Page-Thomas D P, King B, Bard D R. In vivo studies of articular damage mediated by catabolin/interleukin. Ann Rheum Dis 1987; 46: 527-33.

5 Heinegård D. Polydispersity of cartilage proteoglycans. Structural variation with size and buoyant density of the molecules. J Biol Chem 1977; 252: 1980-9.

6 Hardingham T E, Ewins R J, Muir H. Structure and heterogeneity of the protein core and the effect of specific protein modification in the binding of hyaluronate. Biochem J 1976; 157: $127-43$.

7 Markwell M A K. A new solid state reagent to iodinate proteins. 1. Conditions for efficient labelling of antiserum. Anal Biochem 1982; 125: 427-32.

8 Page-Thomas D P. Aspects of synovial biodegradation. In: Glynn L E, Schumberger H D, eds. Experimental models of inflammatory diseases. Berlin, Heidleberg \& New York: Springer, 1977: 353-65. (Bayer Symposium No. 6).

9 Bard D R, Knight C G, Page-Thomas D P. The retention and distribution in the rabbit knee of a radionuclide complexed with a lipophilic chelator in liposomes. Clin Exp Rheumatol 1983; 1: 113-7.

10 McCarty D J, Polcyn R E, Collins P A, Gottschalk A. ${ }^{99 m}$ Technetium scintigraphy in arthritis. 1. Technic and interpretation. Arthritis Rheum 1970; 13: 11-20.

11 Hascall V C, Sajdera S W. Physical properties and polydispersity of proteoglycan from bovine nasal cartilage. J Biol Chem 1970; 245: 4920-30. 